\title{
Ultrasound-Indicated Cervical Cerclage Efficacy Between 16 and 28 Weeks of Gestation in Twin Pregnancy: Retrospective Cohort Study
}

\author{
Li-Ping Yao ${ }^{1,2, *}$ \\ Qing Yang ${ }^{1,2, *}$ \\ Jin-Dan Pei ${ }^{3}$ \\ Yue-Lin $\mathrm{Wu}^{3}$ \\ Sheng Wan ${ }^{3}$ \\ Zhi-Qin Chen ${ }^{4}$ \\ Xiao-Lin Hua ${ }^{1,3}$
}

'Shanghai Key Laboratory of Maternal Fetal Medicine, Department of Ultrasound,

Shanghai First Maternity and Infant Hospital,

School of Medicine, Tongji University,

Shanghai, 200092, People's Republic of

China; ${ }^{2}$ Department of Ultrasound, Shanghai

First Maternity and Infant Hospital, Tongji

University School of Medicine, Shanghai,

200092, People's Republic of China;

${ }^{3}$ Department of Obstetrics, Shanghai First

Maternity and Infant Hospital, School of

Medicine, Tongji University, Shanghai,

200092, People's Republic of China;

${ }^{4}$ Department of Assisted Reproduction,

Shanghai First Maternity and Infant Hospital,

School of Medicine, Tongii University,

Shanghai, 200092, People's Republic of China

*These authors contributed equally to this work

Correspondence: Xiao-Lin Hua

Department of Obstetrics, Shanghai First Maternity and Infant Hospital, School of

Medicine, Tongji University, No. 2699 of

West Gaoke Road, PuDong New District,

Shanghai, 200092, People's Republic of China

Tel +86 21 20261000

$\mathrm{Fax}+862150730190$

Email xiaolin_hua@tongji.edu.cn

\section{Zhi-Qin Chen}

Department of Assisted Reproduction,

Shanghai First Maternity and Infant Hospital,

School of Medicine, Tongji University,

No. 536 of Changle Road, JingAn District,

Shanghai, 200092, People's Republic of China

Tel +86 2I 54035206

Fax +86 21 50730190

Email ptchen I@hotmail.com
Objective: The aim of this study is to determine if cervical cerclage administration reduces the preterm birth (PTB) rate at a gestational age (GA) of 16-28 weeks in women with twin pregnancy. Methods: This is a retrospective cohort study on asymptomatic twin pregnancy with an ultrasound-identified cervix length (CL) of $\leqq 25 \mathrm{~mm}$. The patients were divided into two groups: ultrasound-indicated cerclage (UIC) group and control (expectant management) group. The primary outcome was a PTB rate at $<34$ weeks. A logistic regression was also performed, and a subgroup analysis stratified by $\mathrm{CL}$ and GA at first short cervix diagnosis was planned.

Results: In all 320 women, there were no differences in the overall $<34$-week PTB rates and neonatal outcomes between the UIC group and control group. After performing a multivariate logistic regression analysis, the subgroup analyses were planned. In patients with a CL of $\leqq 15 \mathrm{~mm}$, the $<34$-week PTB rate was significantly decreased in the UIC subgroup compared with the control subgroup $(60.78 \%$ vs $78.26 \%$; odds ratio $(\mathrm{OR})=0.43$, confidence interval $(\mathrm{CI})=95 \%[0.22-0.86]$; and $\mathrm{p}=0.020)$. In patients with a first short cervix diagnosis GA of $\leqq 24$ weeks, the $<34$-week PTB rate was significantly decreased in the UIC subgroup when compared with the control subgroup $(61.54 \%$ vs $84.75 \%$; OR = 0.29 ; $\mathrm{CI}=95 \%[0.13-0.63]$; and $\mathrm{p}=0.001)$. Furthermore, compared with the control groups, the UIC groups had higher mean birth weight, lower perinatal mortality, and lower NICU admission, and the differences were statistically significant.

Conclusion: UIC could significantly reduce the $<34$-week PTB rate and improve perinatal outcomes in patients with a CL of $\leqq 15 \mathrm{~mm}$ or first short cervix diagnosis GA of $\leqq 24$ weeks with asymptomatic twin pregnancy during the second trimester.

Keywords: twin pregnancy, ultrasound-indicated cerclage, cervical length, preterm birth

\section{Introduction}

Despite significant improvements in prenatal and neonatal care over the last decades, preterm birth (PTB) is the world's leading neonatal death cause. ${ }^{1}$ Moreover, children who survive PTB may face the risk of lifelong disability, including vision and hearing loss, cerebral palsy, intellectual impairment, and chronic lung disease. ${ }^{2}$ They are also at greater risk of developing hypertension, diabetes, and developmental problems later in life than other children. ${ }^{2}$ In recent years, the twin pregnancy incidence has increased dramatically due to widespread use of assisted reproductive technology as well as the rise in maternal age. As a result, PTB occurrence is five times greater in twin gestations than in singleton gestations; almost $60 \%$ of twins are born at a GA of $<37$ weeks, and up to $21.2 \%$ are born at a GA of $<34$ weeks. $^{3}$ 
The presence of a short cervix, which is defined by a transvaginal sonographic cervical length (CL) of $\leqq 25 \mathrm{~mm}$ (measured in the second trimester of pregnancy) is a primary risk factor for spontaneous PTB; it has become one of the strongest and most consistent $\mathrm{PTB}$ predictors in asymptomatic women with singleton and twin gestation. ${ }^{4-7}$ Cervical cerclage is a well-known surgical procedure performed during pregnancy; it provides mechanical support to the cervix, thereby decreasing the risk of PTB. ${ }^{8}$ Cerclage placement in patients with singleton gestation, a history of spontaneous PTB, and a short cervix at a GA of $<24$ weeks has been found to decrease the respective incidence rates of PTB and perinatal mortality. ${ }^{9}$

However, the effectiveness of cervical cerclage placement in twin pregnancy remains controversial. From 2013 to 2015, the early years of several related research showed no significant difference between using and not using cervical cerclage in twin pregnancy. However, several recent retrospective studies have shown a potentially positive effect of cerclage placement in twin pregnancy in patients with a short cervix at a GA of $<24$ weeks. In their study, Huang et al stated that cerclage appears to be beneficial in patients with a history of preterm labor, a very short cervix, or cervical dilation. Certain studies also found that cerclage placement significantly reduced the twin pregnancy PTB rate in women with a very short cervix $(<10 \mathrm{~mm}$ or $<15 \mathrm{~mm})$; therefore, it may be effective in certain patients with twin gestation.

Cervical cerclage placement in women with a twin pregnancy is not a routine practice, and its indication is not universally accepted. It is still unknown whether cervical cerclage use is required in asymptomatic twin pregnancy with only a short cervix diagnosis at a GA of either $<24$ weeks or $>24$ weeks. The purpose of the present study is to evaluate ultrasound-indicated cerclage (UIC) (CL $\leqq$ $25 \mathrm{~mm}$ ) efficacy in women with twin pregnancy and no history of preterm labor; comparisons will also be made with women who were managed expectantly in relation to pregnancy and perinatal outcomes.

\section{Materials and Methods}

\section{Patients and Study Design}

The present research is a retrospective cohort study of twin pregnancy in subjects examined throughout pregnancy and delivery at Shanghai First Maternity and Infant Hospital affiliated to Tongji University between January 2014 and December 2020. The subjects had a CL of $\leqq 25 \mathrm{~mm}$ (measured via transvaginal ultrasound [TVU]) at a GA of 16-28 weeks. Exclusion criteria: (1) subjects with genetic or major fetal anomalies; (2) subjects with monochorionicmonoamniotic placentation; (3) subjects who underwent elective pregnancy termination; (4) subjects with a history of PTB, cerclage, or medically indicated PTB (eg, twin-totwin transfusion syndrome, severe preeclampsia, abruption placenta, placenta previa, and active vaginal bleeding); and (5) subjects with history-indicated or physical-indicated cerclage. The participants' flow chart is showed in Figure 1.

Shanghai First Maternity and Infant Hospital has two districts: the eastern district and the western district. In the eastern district, women pregnant with twins who had a CL of $\leqq 25 \mathrm{~mm}$ (UIC group) were routinely treated with cerclage; in contrast, women in the western district who were pregnant with twins and had a CL of $\leqq 25 \mathrm{~mm}$ (control group) were managed expectantly. Apart from cerclage, there were no differences in medical treatments for threatened abortion between the two groups.

The present retrospective study was conducted in accordance with the Declaration of Helsinki and was approved by the Institutional Review Board of Shanghai First Maternity and Infant Hospital (No. KS20186), and written informed consent was obtained from all study participants.

\section{Clinical Treatment}

All patients in the UIC group underwent a McDonald cerclage; they preoperatively received antibiotic prophylaxis (cefazolin or clindamycin in subjects allergic to penicillin), and a standardized transvaginal McDonald's technique for cervical cerclage was performed. All procedures were conducted by two experienced senior physicians, and the patients were under general anesthesia during the procedure. No routine tocolytic therapy or post-procedural prophylactic antibiotic therapy was provided; all women were discharged 24-48 $\mathrm{h}$ after cerclage placement. A dosage of $200 \mathrm{mg}$ adjunctive vaginal progesterone was administered daily for 7 consecutive days after cerclage. The cerclage was removed at a GA of 37 weeks or in the case of a Cesarean section if indicated.

All patients in the control group received therapy with $200 \mathrm{mg}$ adjuvant vaginal progesterone daily for 7 consecutive days after short cervix diagnosis.

\section{Data Collection}

Information was abstracted from the hospital maternalfetal wards' electronic medical record database; two review authors extracted the data, which were then checked for accuracy. Extracted data: patient characteristics; full-term and spontaneous preterm (GA of 20-36 weeks) delivery history; first-trimester pregnancy loss 


\section{7 records given by the eastern district}

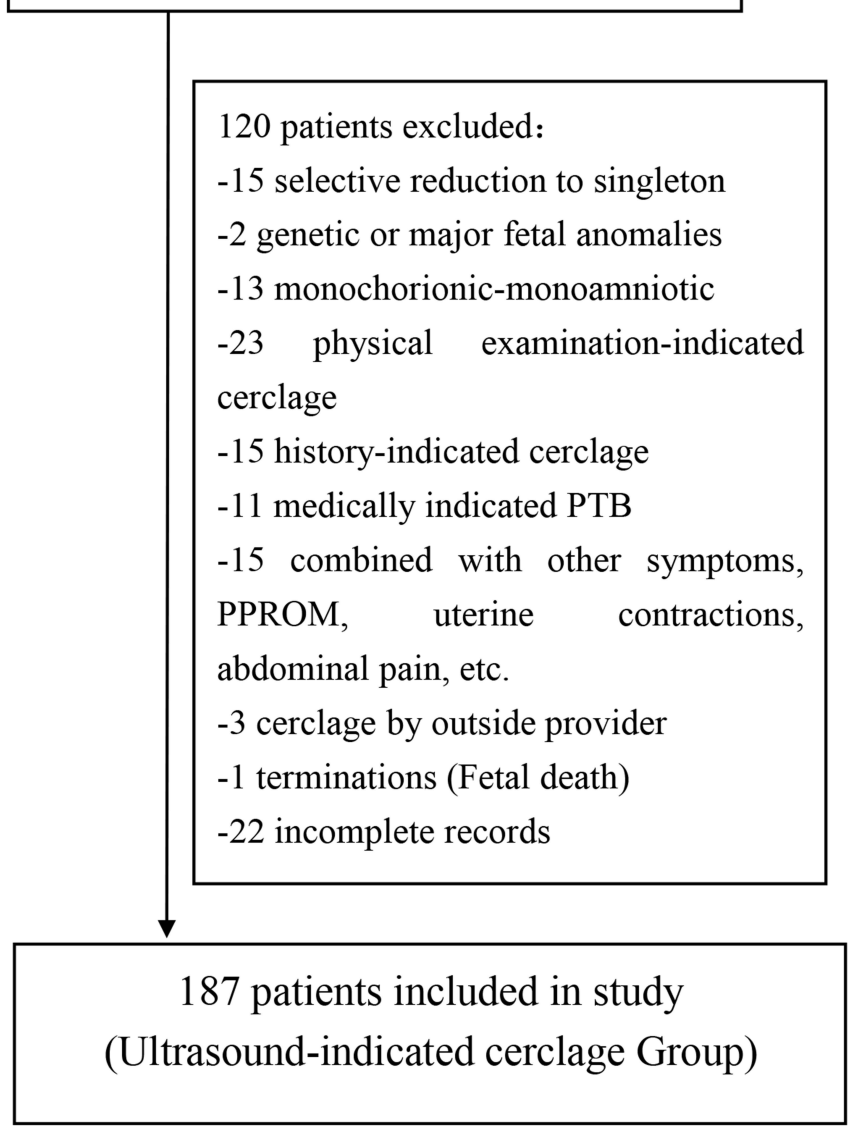

\section{6 records given by the western district}

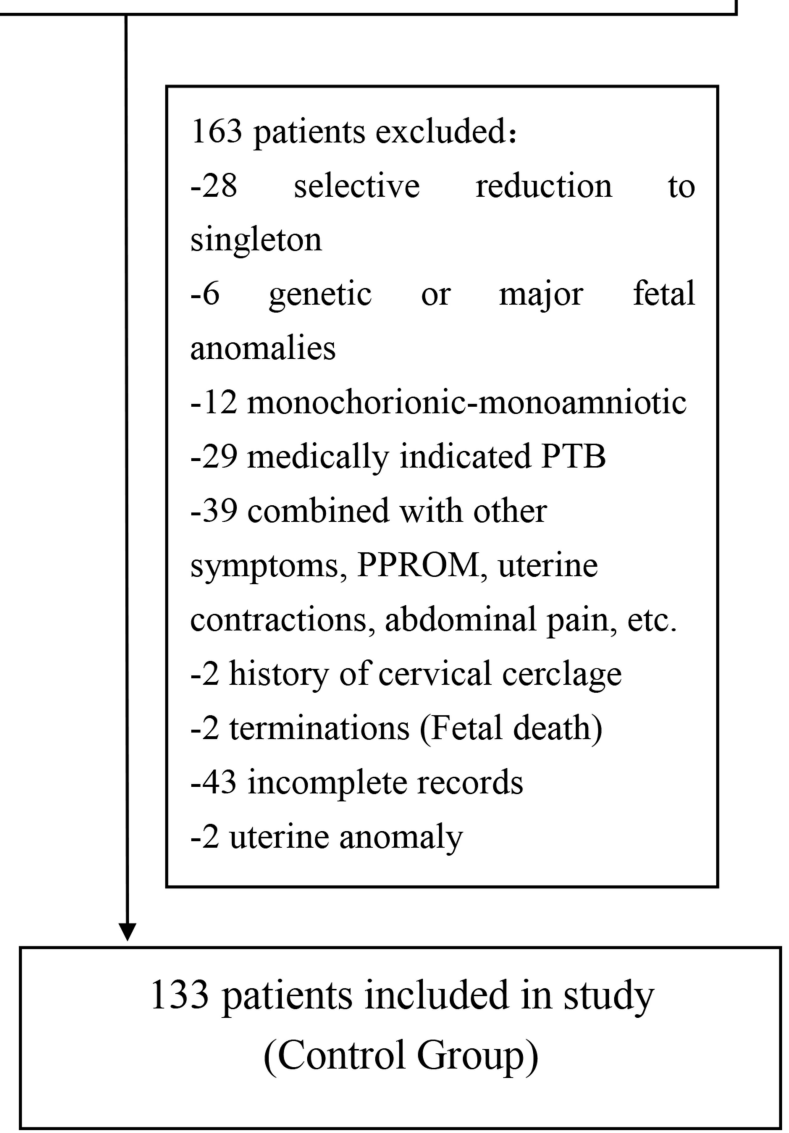

Figure I The participants' flow chart.

(GA of $<14$ weeks); history of uterine instrumentation (eg, dilatation and curettage or operative hysteroscopy), uterine anomalies, and assisted reproductive technology use; gestational age (GA) at first short cervix diagnosis and cerclage placement; chorionicity; pregnancy-related hypertensive disorders; gestational diabetes mellitus; other major maternal comorbidities (cancer or heart, kidney, liver, lung, and autoimmune diseases); GA at delivery; delivery mode; premature rupture of membranes (PPROM); intrauterine infection; placental abruption; birth weight; and neonatal intensive care unit (NICU) admission.

The patient GA was calculated during the first-trimester ultrasound examination, and chorionicity was determined via first-trimester ultrasound evaluation. The patient $\mathrm{CL}$ was determined by trained sonographers using a standardized TVU technique obtained at a GA of 1628 weeks. Cervical length measurements were performed in the sagittal plane with the entire cervical canal visible, calipers placed on the internal and external os, with an empty bladder and minimal pressure. Three measurements were performed, and the shortest value was noted. The decision to perform cerclage was based on individual physician and patient preferences.

\section{Outcome Measures}

The primary outcome was a PTB rate at $<34$ weeks, and the secondary outcomes were PTB rates at $<37$ weeks, $<28$ weeks, and $<32$ weeks; perinatal mortality; birth weight; NICU admission; and low birth weight $(<2500 \mathrm{~g})$ and very low birth weight $(<1500 \mathrm{~g})$ rates.

The subgroup analysis was performed by stratifying women into the CL $\leqq 15 \mathrm{~mm}$ subgroup and the CL $>15 \mathrm{~mm}$ subgroup (CL measured via TVU). The subgroup analysis of women diagnosed with short cervix at a GA of $\leqq 24$ weeks and GA of $>24$ weeks was also planned. The corresponding outcomes were compared between the two groups. 


\section{Statistical Analysis}

Normally distributed continuous variables were presented as mean \pm standard deviation, and non-normally distributed continuous variables were presented as the median (interquartile range). Categorical variables were written as $\mathrm{n}(\%)$. The chi-square test or Fisher's exact test was used to assess the difference significance between groups for categorical variables, the Mann-Whitney $U$-test or non-parametric test was used for non-normally distributed continuous variables, and the $t$-test was used for normally distributed continuous variables.

A logistic regression was applied to control confounding variables and provide an adjusted odds ratio (OR) with a $95 \%$ confidence interval (CI). Unadjusted data were analyzed using crude ORs. In addition, the analysis of patient GA at delivery in each group was performed using the Kaplan-Meier (KM) method; the differences between the curves were assessed using the Log rank test. The Cox proportional hazards model was used to calculate the hazard ratio $(\mathrm{HR})(\mathrm{CI}=95 \%)$ for $\mathrm{GA}$ at delivery.

All $\mathrm{p}$ values were two-sided, and a $\mathrm{p}$ value of $<0.05$ was considered statistically significant. The Statistical Package for Social Sciences (SPSS) 24.0 software (SPSS Inc., Chicago, IL, USA) was used to perform the statistical analysis.

\section{Results}

\section{Patient Characteristics}

A total of 320 women were enrolled in the present study. The women were divided into two groups: the UIC group $(\mathrm{n}=$ $187)$ and the control group $(n=133)$. Women in the UIC group underwent cerclage, and women in the control group were expectantly managed. A total of 2 patients underwent a re-cerclage due to ligation displacement. Technical success with no immediate procedure-related complications was achieved in all cerclage placements. The demographic characteristics of the two groups and the cervical length at the time of diagnosis are presented in Table 1.

\section{Delivery and Neonatal Outcomes in All Short Cervix Twin Pregnancies}

The delivery and neonatal outcomes of all cases with a short cervix are shown in Table 2. The comparisons between the UIC group and the control group showed comparable PTB rates at $<34$ weeks $(50.80 \%$ vs $54.14 \%$; OR $=0.88[0.56-$ $1.37]$; and $\mathrm{p}=0.572),<37$ weeks $(81.28$ vs $84.21 \%$;
Table I Demographic and Gestational Characteristics

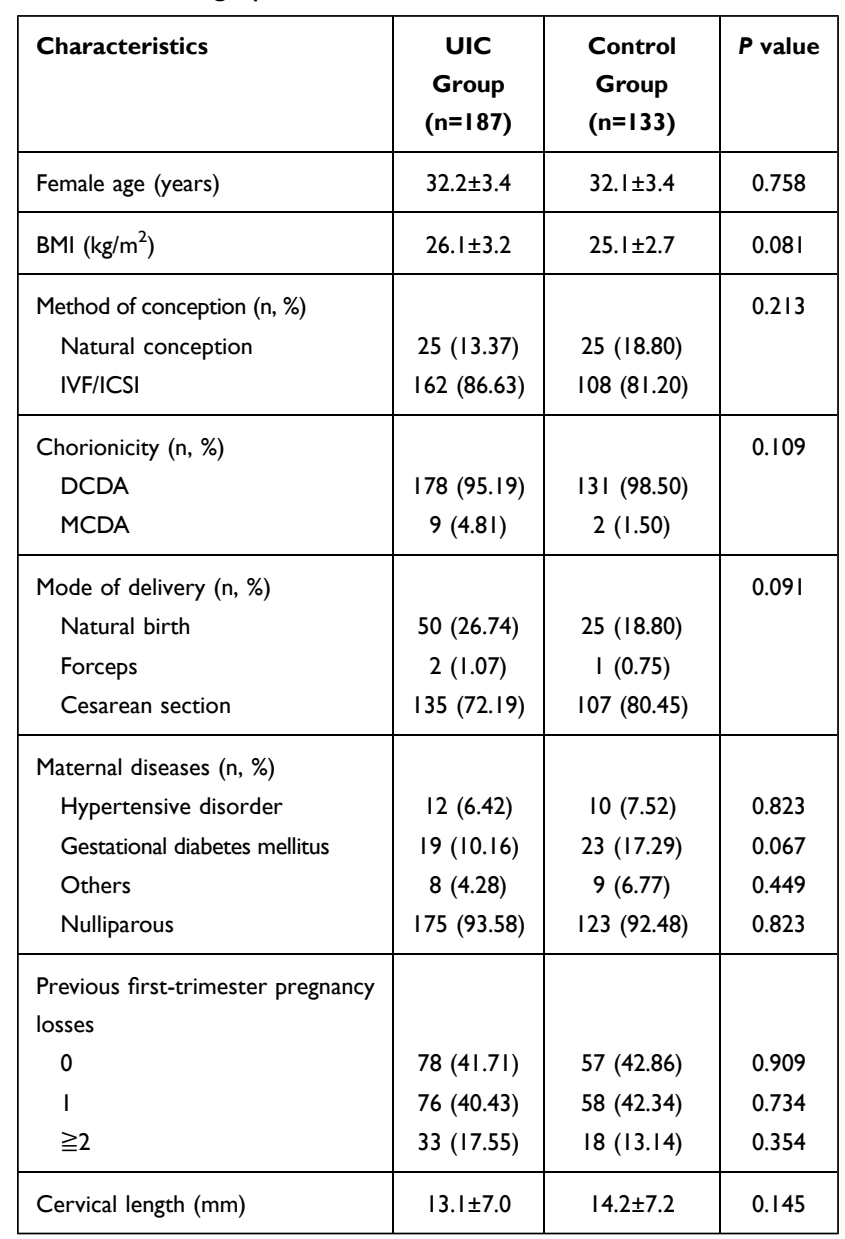

Abbreviations: BMI, body mass index; IVF, in vitro fertilization; ICSI, intracytoplasmic sperm injection; DCDA, dichorionic-diamniotic; MCDA, monochorionicdiamniotic.

$\mathrm{OR}=0.81[0.45-1.47]$; and $\mathrm{p}=0.552),<32$ weeks $(36.90 \%$ vs $41.35 \%$; OR $=0.82$ [0.52-1.29]; and $\mathrm{p}=0.485)$, and $<28$ weeks $(12.30 \%$ vs $19.55 \%$; OR $=0.58[0.31-1.06]$; and $\mathrm{p}=0.084)$; comparable patient GA at delivery $(32.49 \pm 4.43$ weeks vs $32.00 \pm 4.97$ weeks; $p=0.357$ ); and no significant differences in perinatal mortality $(14.17 \%$ vs $18.05 \%$; $\mathrm{p}=0.189)$, mean birth weight (1927 g vs $2150 \mathrm{~g}$; $\mathrm{p}=0.913)$, low infant birth weight rates $(75.94 \%$ vs $80.45 \% ; \mathrm{p}=0.178$ ), and very low infant birth weight rates $(32.09 \%$ vs $36.84 \% ; p=0.236)$. There were no significant differences in NICU admission among live-born neonates in the UIC group compared with the control group ( $47.35 \%$ vs $55.05 \% ; p=0.095)$. During labor, the incidence of PPROM was significantly lower in the UIC group than in the control group $(21.93 \%$ vs $32.33 \%$; OR $=1.70$ [1.03-2.81]; and $\mathrm{p}=0.040$ ), and no difference of the incidence of intrauterine infection between the two groups $(1.07 \%$ vs $0.75 \%$; $\mathrm{p}=0.771)$. 
Table 2 Delivery and Neonatal Outcomes of Twin Pregnancies with a Short Cervix

\begin{tabular}{|c|c|c|c|c|}
\hline Variable & UIC Group $(n=187)$ & Control Group $(n=133)$ & OR $(95 \% \mathrm{CI})$ & $P$ value \\
\hline PTB $<34$ week & $95(50.80)$ & $72(54.14)$ & $0.88(0.56-1.37)$ & 0.572 \\
\hline PTB $<37$ week & $152(81.28)$ & $112(84.21)$ & $0.8 \mathrm{I}(0.45-1.47)$ & 0.552 \\
\hline PTB $<32$ week & $69(36.90)$ & $55(4 I .35)$ & $0.82(0.52-1.29)$ & 0.485 \\
\hline PTB $<28$ week & $23(12.30)$ & $26(19.55)$ & $0.58(0.3 \mathrm{I}-1.06)$ & 0.084 \\
\hline PPROM (n, \%) & $41(21.93)$ & $43(32.33)$ & $\mathrm{I} .70(\mathrm{I} .03-2.8 \mathrm{I})$ & $0.040 *$ \\
\hline Intrauterine infection $(\mathrm{n}, \%)$ & $2(1.07)$ & I $(0.75)$ & $0.70(0.06-7.80)$ & 0.771 \\
\hline GA at delivery (week) & $32.49 \pm 4.43$ & $32.00 \pm 4.97$ & & 0.357 \\
\hline Perinatal mortality (n, \%) & $53(14.17)$ & $48(18.05)$ & $1.33(0.87-2.04)$ & 0.189 \\
\hline Birth weight $(g)$ & $1927(1320,2460)$ & $2150(1266,2395)$ & & 0.913 \\
\hline LBW $<2500 \mathrm{~g}$ & $284(75.94)$ & $214(80.45)$ & $0.77(0.52-1.13)$ & 0.178 \\
\hline VLBW $<1500 \mathrm{~g}$ & 120 (32.09) & $98(36.84)$ & $0.81(0.58-1.13)$ & 0.236 \\
\hline Admission to NICU (born alive only) & $|52 / 32|(47.35)$ & $120 / 2 \mid 8(55.05)$ & $1.36(0.96-1.92)$ & 0.095 \\
\hline
\end{tabular}

Note: $* P<0.05$.

Abbreviations: OR, odds ratio; $\mathrm{Cl}$, confidence interval; PPROM, premature rupture of membranes; PTB, preterm birth; GA, gestational age; LBW, low birth weight; VLBW, very low birth weight; $\mathrm{NICU}$, neonatal intensive care unit.

\section{Logistic Regression Analysis for PTB Risk at $<34$ Weeks}

Univariate regression analysis demonstrated that short cervix diagnosis time (crude $\mathrm{OR}=0.21 ; \mathrm{CI}=95 \%$ [1.12-1.30]), and cervical length (crude $\mathrm{OR}=1.11 ; \mathrm{CI}=95 \%$ [1.08-1.15]) were the risk factors for PTB at $<34$ weeks (Table 3).

A multivariate logistic regression analysis demonstrated that cerclage administration (adjusted $\mathrm{OR}=0.20 ; \mathrm{CI}=95 \%$ [0.06-0.66]), short cervix diagnosis time (adjusted $\mathrm{OR}=1.39$; $\mathrm{CI}=95 \%$ [1.18-1.64]), and cervical length (adjusted OR = $1.15 ; \mathrm{CI}=95 \%[1.07-1.24])$ were the independent risk factors for PTB at $<34$ weeks (Table 3).

\section{Delivery and Neonatal Subgroup Analysis Outcomes}

The subgroup analysis delivery outcomes of twin pregnancies are shown in Table 4, and the subgroup analysis of neonatal outcomes are shown in Table 5.
A total of 102 women in the UIC group and 69 women in control group were included in the subgroup analysis for women with a CL of $\leqq 15 \mathrm{~mm}$. PTB rates at $<34$ weeks $(60.78 \%$ vs $78.26 \%$; OR $=0.43 ; \mathrm{CI}=95 \%[0.22-0.86]$; and $\mathrm{p}=0.020),<32$ weeks $(45.10 \%$ vs $63.77 \%$; OR $=0.47$ [0.25-0.87]; and $\mathrm{p}=0.019)$, and $<28$ weeks $(14.71 \%$ vs $30.43 \%$; OR $=0.39[0.19-0.84]$; and $\mathrm{p}=0.021)$, were significant lower in the UIC group than in the control group. There was no significant difference in the PTB rate at $<37$ weeks between the two groups. The patient GA at delivery was longer in the UIC group than in the control group ( $31.55 \pm 4.48$ weeks vs $30.09 \pm 4.84$ weeks), and the mean birth weight was significantly higher in the UIC group than in the control group (1735 $\pm 746 \mathrm{~g}$ vs $1520 \pm 824 \mathrm{~g} ; \mathrm{p}=0.021)$. Perinatal mortality $(15.20 \%$ vs $25.36 \% ; p=0.025)$, the rates of low infant birth weight $(80.88 \%$ vs $92.75 \% ; \mathrm{p}=0.003)$ and very low infant birth weight $(39.22 \%$ vs $53.62 \% ; \mathrm{p}=0.011)$, and $\mathrm{NICU}$

Table 3 Logistic Regression Analysis for PTB Risk at $<34$ Weeks

\begin{tabular}{|l|c|c|c|c|}
\hline Variables & Crude OR (95\% Cl) & P value & Adjusted OR (95\% CI) & P value \\
\hline Cerclage or not & $0.83(0.53-1.29)$ & 0.398 & $0.20(0.06-0.66)$ & $0.008^{*}$ \\
Diagnosis time for short cervix & $0.2 I(I .12-1.30)$ & $0.000^{*}$ & $1.39(1.18-1.64)$ & $0.000^{*}$ \\
Cervical length & $1.1 I(I .08-1.15)$ & $0.000^{*}$ & $1.15(1.07-1.24)$ & $0.00 I^{*}$ \\
Female age & $1.06(I .00-1.13)$ & 0.055 & $1.09(0.97-1.22)$ & 0.160 \\
Body mass index & $0.99(0.87-1.13)$ & 0.854 & $1.12(0.93-1.35)$ & 0.229 \\
Method of pregnancy & $1.91(0.94-3.88)$ & 0.074 & $1.44(0.49-4.23)$ & 0.513 \\
Maternal diseases & $0.75(0.45-1.28)$ & 0.293 & $0.35(0.11-1.15)$ & 0.083 \\
Nulliparous & $2.07(0.82-5.23)$ & 1.222 & $0.40(0.07-2.44)$ & 0.318 \\
Previous first-trimester pregnancy losses & $0.77(0.49-1.20)$ & 0.242 & $1.6 I(0.65-3.97)$ & 0.305 \\
\hline
\end{tabular}

Note: $* p<0.05$.

Abbreviations: $\mathrm{OR}$, odds ratio; $\mathrm{Cl}$, confidence interval. 
Table 4 Subgroup Analysis Delivery Outcomes of Twin Pregnancies

\begin{tabular}{|c|c|c|c|c|}
\hline & UIC Group & Control Group & OR $(95 \% \mathrm{CI})$ & $P$ value \\
\hline \multicolumn{5}{|c|}{ Subgroup I: According to cervical length } \\
\hline \multicolumn{5}{|l|}{ PTB $<34$ week } \\
\hline $\mathrm{CL} \leqq \mathrm{I} 5 \mathrm{~mm}$ & $62 / 102(60.78)$ & $54 / 69(78.26)$ & $0.43(0.22-0.86)$ & $0.020 *$ \\
\hline$C L>15 \mathrm{~mm}$ & $33 / 85(38.82)$ & $18 / 64(28.13)$ & $1.62(0.81-3.26)$ & 0.222 \\
\hline \multicolumn{5}{|l|}{ PTB $<37$ week } \\
\hline $\mathrm{CL} \leqq 15 \mathrm{~mm}$ & $87 / 102(85.29)$ & $65 / 69(94.20)$ & $0.36(0.11-1.13)$ & 0.084 \\
\hline$C L>15 \mathrm{~mm}$ & 65/85 (76.47) & $47 / 64(73.43)$ & $1.18(0.56-2.48)$ & 0.705 \\
\hline \multicolumn{5}{|l|}{ PTB $<32$ week } \\
\hline $\mathrm{CL} \leqq 15 \mathrm{~mm}$ & $46 / 102(45.10)$ & $44 / 69(63.77)$ & $0.47(0.25-0.87)$ & $0.019 *$ \\
\hline$C L>15 \mathrm{~mm}$ & $23 / 85(27.06)$ & $11 / 64(17.19)$ & $1.79(0.80-4.00)$ & 0.172 \\
\hline \multicolumn{5}{|l|}{ PTB $<28$ week } \\
\hline $\mathrm{CL} \leqq 15 \mathrm{~mm}$ & $15 / 102(14.71)$ & $21 / 69(30.43)$ & $0.39(0.19-0.84)$ & $0.021 *$ \\
\hline $\mathrm{CL}>15 \mathrm{~mm}$ & $8 / 85(9.4 I)$ & $5 / 64(7.8 I)$ & $1.23(0.38-3.94)$ & 0.732 \\
\hline \multicolumn{5}{|l|}{ GA at delivery (week) } \\
\hline $\mathrm{CL} \leqq 15 \mathrm{~mm}$ & $31.55 \pm 4.48$ & $30.09 \pm 4.84$ & & $0.034 *$ \\
\hline$C L>15 \mathrm{~mm}$ & $33.63 \pm 4.12$ & $34.14 \pm 4.17$ & & 0.452 \\
\hline \multicolumn{5}{|c|}{ Subgroup 2: According to GA at diagnosis of short cervix } \\
\hline \multicolumn{5}{|l|}{ PTB $<34$ week } \\
\hline $\mathrm{GA} \leqq 24$ week & $84 / 143(6 I .54)$ & $51 / 59(84.75)$ & $0.29(0.13-0.63)$ & $0.001 *$ \\
\hline GA>24 week & I I/44 (20.45) & $21 / 74(32.43)$ & $0.54(0.22-1.29)$ & 0.205 \\
\hline \multicolumn{5}{|l|}{ PTB $<37$ week } \\
\hline $\mathrm{GA} \leqq 24$ week & $119 / 143(83.21)$ & $57 / 59(96.61)$ & $0.17(0.04-0.76)$ & $0.010 *$ \\
\hline GA>24 week & $33 / 44(75)$ & $55 / 74(74.32)$ & $1.04(0.44-2.45)$ & 0.935 \\
\hline \multicolumn{5}{|l|}{ PTB $<32$ week } \\
\hline $\mathrm{GA} \leqq 24$ week & $6 \mathrm{I} / 143(46.15)$ & 44/59 (74.58) & $0.29(0.15-0.57)$ & $0.000 *$ \\
\hline GA>24 week & $8 / 44(18.18)$ & $\mathrm{II} / 74(13.5 \mathrm{I})$ & $1.27(0.47-3.46)$ & 0.796 \\
\hline \multicolumn{5}{|l|}{ PTB $<28$ week } \\
\hline $\mathrm{GA} \leqq 24$ week & $22 / 143(18.18)$ & $24 / 59$ (38.98) & $0.35(0.18-0.68)$ & $0.003 *$ \\
\hline GA>24 week & I/44 (4.55) & $2 / 74(2.70)$ & $0.84(0.07-9.5 \mathrm{I})$ & 0.886 \\
\hline \multicolumn{5}{|l|}{ GA at delivery (week) } \\
\hline $\mathrm{GA} \leqq 24$ week & $31.75 \pm 4.57$ & $28.20 \pm 4.99$ & & $0.000 *$ \\
\hline $\mathrm{GA}>24$ week & $34.73 \pm 3.08$ & $34.91 \pm 2.43$ & & 0.722 \\
\hline
\end{tabular}

Note: $* P<0.05$.

Abbreviations: OR, odds ratio; $\mathrm{Cl}$, confidence interval; PTB, preterm birth; $\mathrm{CL}$, cervical length; GA, gestational age.

admission $(56.07 \%$ vs $72.82 \% ; \mathrm{p}=0.007)$ were significant lower in UIC group than in the control group.

In women with a CL of $\leqq 15 \mathrm{~mm}$, the $\mathrm{KM}$ analysis showed a significantly higher cumulative incidence of successful delivery in the cerclage group than in the control group (log rank test, $\mathrm{x} 2=5.74, \mathrm{p}=0.017 ; \mathrm{HR}=1.55$, $\mathrm{CI}=95 \%$ [1.08-2.24], $\mathrm{p}=0.018)($ Figure 2A).

A total of 85 women in UIC group and 64 women in control group had a CL of $>15 \mathrm{~mm}$. PTB rates at $<34$ weeks, $<37$ weeks, $<32$ weeks, and $<28$ weeks were comparable between groups. Perinatal mortality $(12.94 \%$ vs $10.16 \% ; \mathrm{p}=0.586)$, low birth weight rate $(70 \%$ vs $67.19 \% ; \mathrm{p}=0.616)$, very low birth weight rate $(23.53 \%$ vs $18.75 \% ; \mathrm{p}=0.393)$, and NICU admission $(37.16 \%$ vs $39.13 \% ; p=0.798)$ in the two groups were also similar. There were no significant differences in GA at delivery (33.54 \pm 4.17 weeks vs $34.03 \pm 4.28$ weeks; $p=0.489)$ and birth weight $(1960 \pm 777 \mathrm{~g}$ vs $2098 \pm 761 \mathrm{~g}$; and $\mathrm{p}=$ $0.126)$ between the two groups. The KM analysis in the CL $>15 \mathrm{~mm}$ subgroup showed no significant difference in 
Table 5 Subgroup Analysis Neonatal Outcomes of Twin Pregnancies

\begin{tabular}{|c|c|c|c|c|}
\hline & UIC Group & Control Group & OR $(95 \% \mathrm{Cl})$ & $P$ value \\
\hline \multicolumn{5}{|c|}{ Subgroup I: According to cervical length } \\
\hline \multicolumn{5}{|l|}{ Perinatal mortality (n, \%) } \\
\hline $\mathrm{CL} \leqq 15 \mathrm{~mm}$ & $31 / 204(15.20)$ & $35 / 138(25.36)$ & $1.90(1.10-3.26)$ & $0.025^{*}$ \\
\hline $\mathrm{CL}>15 \mathrm{~mm}$ & $22 / 170(12.94)$ & $13 / 128(10.16)$ & $0.76(0.37-1.57)$ & 0.586 \\
\hline \multicolumn{5}{|l|}{ Birth Weight (g) } \\
\hline $\mathrm{CL} \leqq 15 \mathrm{~mm}$ & $1735 \pm 746$ & $1520 \pm 824$ & & $0.02 I^{*}$ \\
\hline $\mathrm{CL}>15 \mathrm{~mm}$ & $1960 \pm 777$ & $2098 \pm 761$ & & 0.126 \\
\hline \multicolumn{5}{|l|}{ Low birth weight $(<2500 \mathrm{~g})$} \\
\hline $\mathrm{CL} \leqq 15 \mathrm{~mm}$ & I65/204 (80.88) & I28/I38 (92.75) & $0.33(0.16-0.69)$ & $0.003^{*}$ \\
\hline$C L>15 \mathrm{~mm}$ & $119 / 170(70)$ & $86 / 128(67.19)$ & $1.14(0.70-1.87)$ & 0.616 \\
\hline \multicolumn{5}{|l|}{ Very low birth weight $(<1500 \mathrm{~g})$} \\
\hline $\mathrm{CL} \leqq 15 \mathrm{~mm}$ & $80 / 204(39.22)$ & $74 / 138(53.62)$ & $0.56(0.36-0.86)$ & $0.011^{*}$ \\
\hline$C L>15 \mathrm{~mm}$ & $40 / 170(23.53)$ & $24 / 128(18.75)$ & $1.33(0.76-2.35)$ & 0.393 \\
\hline \multicolumn{5}{|l|}{ Admission to NICU (born alive only) } \\
\hline $\mathrm{CL} \leqq 15 \mathrm{~mm}$ & $97 / 173(56.07)$ & $75 / 103(72.82)$ & $2.10(1.24-3.56)$ & $0.007^{*}$ \\
\hline $\mathrm{CL}>15 \mathrm{~mm}$ & $55 / 148(37.16)$ & $45 / 115(39.13)$ & $1.09(0.66-1.80)$ & 0.798 \\
\hline \multicolumn{5}{|c|}{ Subgroup 2: According to GA at diagnosis of short cervix } \\
\hline \multicolumn{5}{|l|}{ Perinatal mortality (n, \%) } \\
\hline $\mathrm{GA} \leqq 24$ week & $49 / 286(17.13)$ & $46 / 118$ (38.98) & $2.01(1.27-3.18)$ & $0.004 *$ \\
\hline GA>24 week & $4 / 88(4.55)$ & $2 / 148(1.35)$ & $0.29(0.05-1.60)$ & 0.132 \\
\hline \multicolumn{5}{|l|}{ Birth Weight (g) } \\
\hline $\mathrm{GA} \leqq 24$ week & 1792 (125I, 239I) & $1200(450,1930)$ & & $0.000 *$ \\
\hline GA>24 week & $2405(1800,2723)$ & $2325(2181,2555)$ & & 0.973 \\
\hline \multicolumn{5}{|l|}{ Low birth weight $(<2500 \mathrm{~g})$} \\
\hline $\mathrm{GA} \leqq 24$ week & $232 / 286(81.12)$ & $110 / 118(93.22)$ & $0.32(0.15-0.70)$ & $0.002 *$ \\
\hline GA>24 week & $52 / 88(59.09)$ & I04/I48 (70.27) & $0.61(0.35-1.06)$ & 0.089 \\
\hline \multicolumn{5}{|l|}{ Very low birth weight $(<1500 \mathrm{~g})$} \\
\hline $\mathrm{GA} \leqq 24$ week & $106 / 286(37.06)$ & $84 / 118$ (7I.19) & $0.24(0.15-0.38)$ & $0.000 *$ \\
\hline $\mathrm{GA}>24$ week & |4/88 (15.9I) & |4/I48 (9.46) & I.8I (0.82-4.00) & 0.150 \\
\hline \multicolumn{5}{|l|}{$\begin{array}{l}\text { Admission to NICU (born alive } \\
\text { only) }\end{array}$} \\
\hline $\mathrm{GA} \leqq 24$ week & I22/237 (5I.48) & $52 / 72(72.22)$ & $2.45(1.38-4.36)$ & $0.002 *$ \\
\hline GA>24 week & $30 / 84$ (35.7I) & $68 / 146(46.58)$ & $1.57(0.90-2.73)$ & 0.128 \\
\hline
\end{tabular}

Note: $* P<0.05$.

Abbreviations: $\mathrm{OR}$, odds ratio; $\mathrm{Cl}$, confidence interval; $\mathrm{CL}$, cervical length; $\mathrm{NICU}$, neonatal intensive care unit; GA, gestational age.

the cumulative number of successful deliveries in the cerclage group compared with the control group (log rank test, $\mathrm{x} 2=1.76 ; \mathrm{p}=0.185$ ) (Figure $2 \mathrm{~B}$ ).

A total of 143 women in the UIC group and 59 women in control group had a first short cervix diagnosis time of GA $\leqq$ 24 weeks; here, the PTB rates at $<34$ weeks $(61.54 \%$ vs $84.75 \%$; OR $=0.29$ [0.13-0.63]; and $\mathrm{p}=0.001),<37$ weeks $(83.21 \%$ vs $96.61 \%$; OR $=0.17[0.04-0.76])$; and $\mathrm{p}=0.010)$,
$<32$ weeks ( $46.15 \%$ vs $74.58 \%$; $\mathrm{OR}=0.29$ [0.15-0.57]; and $\mathrm{p}=0.000)$, and $<28$ weeks ( $18.18 \%$ vs $38.98 \%$; OR $=0.35$ [0.18-0.68]; and $\mathrm{p}=0.003$ ) were significantly lower in UIC group compared with the control group. The GA at delivery ( $31.75 \pm 4.57$ weeks vs $28.20 \pm 4.99$ weeks; $p=0.000)$ and the diagnose-to-delivery interval $(11.01 \pm 4.82$ weeks vs $6.98 \pm$ 3.84 weeks; $p=0.000$ ) were longer in the UIC group compared with the control group. Moreover, the median birth 

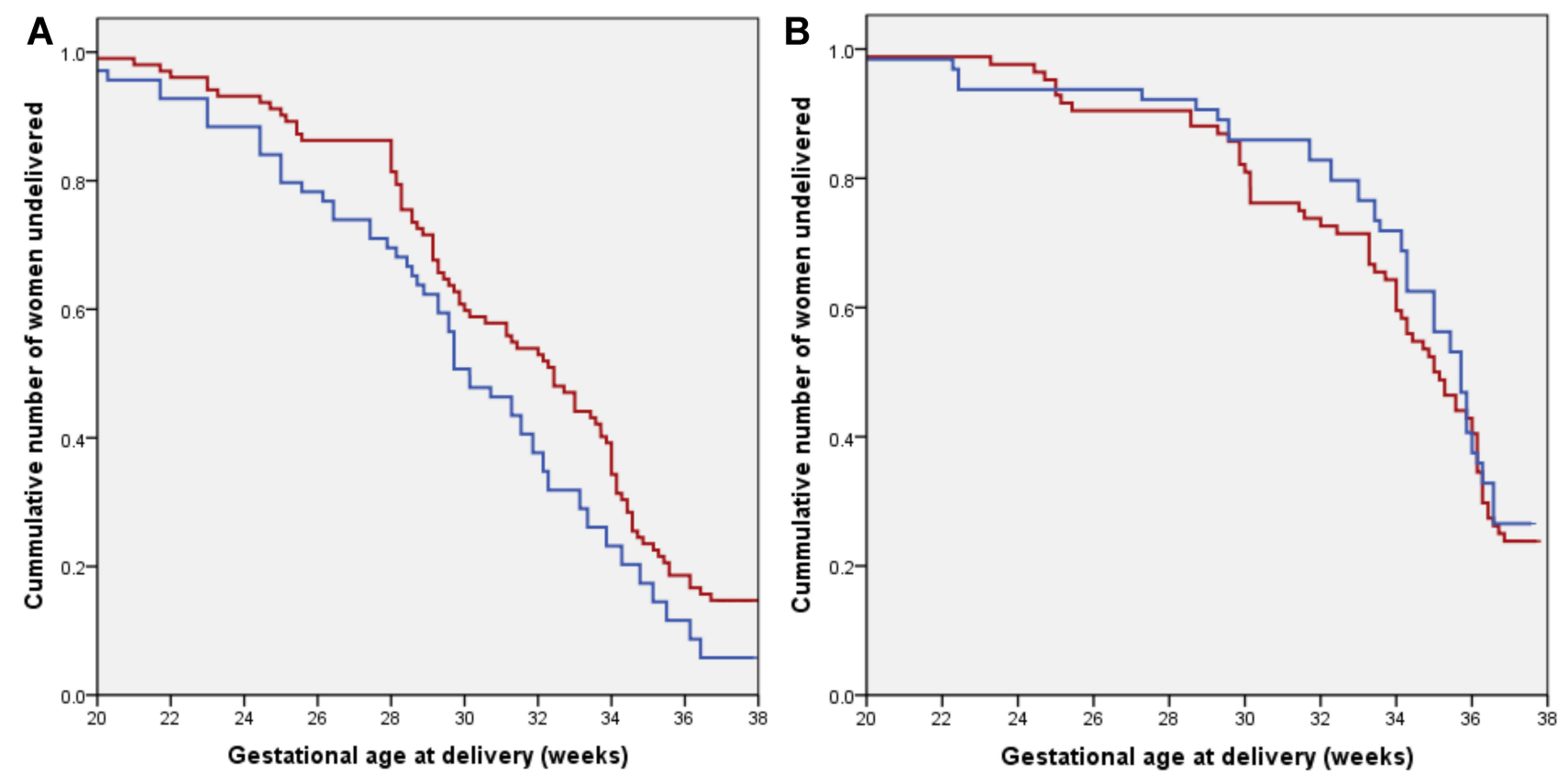

Figure 2 KM curves generated from CL subgroup analysis. Proportion KM curves in women with twin pregnancy and a short cervix with no delivery across gestation and treated with cervical cerclages (UIC group) compared with the expectant management (control group). CL-based subgroup analysis; (A) showed a CL of $\leqq I 5$ mm, and (B) showed a $\mathrm{CL}$ of $>15 \mathrm{~mm}$. Group comparison using the Log rank test showed a significant difference $(\mathrm{HR}=1.55 ; \mathrm{Cl}=95 \%[\mathrm{I} .08-2.24]$; and $\mathrm{P}=0.018)$ in $(\mathbf{A})$, with no difference between the two groups in (B). Red curve cases with a short cervix treated with ultrasound-indicated cerclage; blue curve cases with expectant management.

weight was heavier in UIC group compared with the control group (1792 g vs $1200 \mathrm{~g} ; \mathrm{p}=0.000)$. However, perinatal mortality $(17.13 \%$ vs $38.98 \% ; \mathrm{p}=0.000)$ as well as the rates of low birth weight $(81.12 \%$ vs $93.22 \% ; \mathrm{p}=0.002)$ and very low birth weight $(37.06 \%$ vs $71.19 \% ; \mathrm{p}=0.000)$, and NICU admission (51.48\% vs $72.22 \% ; \mathrm{p}=0.002)$ were lower in UIC group compared with the control group. The KM analysis in the present patient subgroup showed a significantly higher cumulative incidence of successful deliveries in the UIC group compared with the control group (log rank test, $\mathrm{x} 2=23.05, \mathrm{p}=0.000 ; \mathrm{HR}=2.29, \mathrm{CI}=95 \%[1.61-3.26]$, and $\mathrm{p}=0.000$ ) (Figure $3 \mathrm{~A}$ ).

A total of 44 women in the UIC group and 74 women in control group had a short cervix diagnosis time of $>24$ weeks; here, the PTB rates at $<34$ weeks, $<37$ weeks, $<32$ weeks, and $<28$ weeks were comparable between the two groups. Perinatal mortality $(4.55 \%$ vs $1.35 \% ; \mathrm{p}=0.132)$ as well as the rates of low birth weight $(59.09 \%$ vs $70.27 \%$; $\mathrm{p}=0.089)$, very low birth weight $(15.91 \%$ vs $9.46 \%$; $\mathrm{p}=0.150)$, and NICU admission (35.71\% vs $46.58 \%$; $\mathrm{p}=0.128)$ in the two groups were also similar. There were no significant differences in the GA at delivery $(34.73 \pm 3.08$ weeks vs $34.91 \pm 2.43$ weeks; $p=0.722)$ and the median birth weight (2405 g vs $2325 \mathrm{~g} ; \mathrm{p}=0.973$ ) between the two groups. The KM analysis in the present subgroup showed no significant difference in the cumulative number of successful deliveries in the UIC group compared with the control group (log rank test, $\chi^{2}$ $=0.07 ; \mathrm{p}=0.785)$ (Figure $3 \mathrm{~B})$.

\section{Discussion}

The present retrospective study evaluated UIC efficacy in asymptomatic twin gestations with second trimester TVU screening. No differences were found in the PTB rate $(<34$ weeks) or the delivery and neonatal outcomes in the comparison of women with twin pregnancy and a short cervix undergoing UIC and women with no intervention. However, UIC had a significant effect on reducing the PTB rate, and the neonatal outcome was significantly improved in women with a CL of $\leq 15 \mathrm{~mm}$ and a short cervix diagnosis time of GA $\leqq 24$ weeks compared with women who were expectantly managed.

It is well accepted that women with twin pregnancies have a high risk of spontaneous PTB; especially in women with a short cervix. ${ }^{7}$ Therefore, preventing spontaneous PTB in twin pregnancy poses a challenging clinical dilemma for both patients and physicians. Cervical cerclage has been used to prolong pregnancy and prevent morbidity and mortality associated with premature birth for nearly half a century. ${ }^{8}$ Many studies have proven that cerclage is effective in PTB prevention in singleton pregnancy. ${ }^{2}$ However, no definite statement has been 

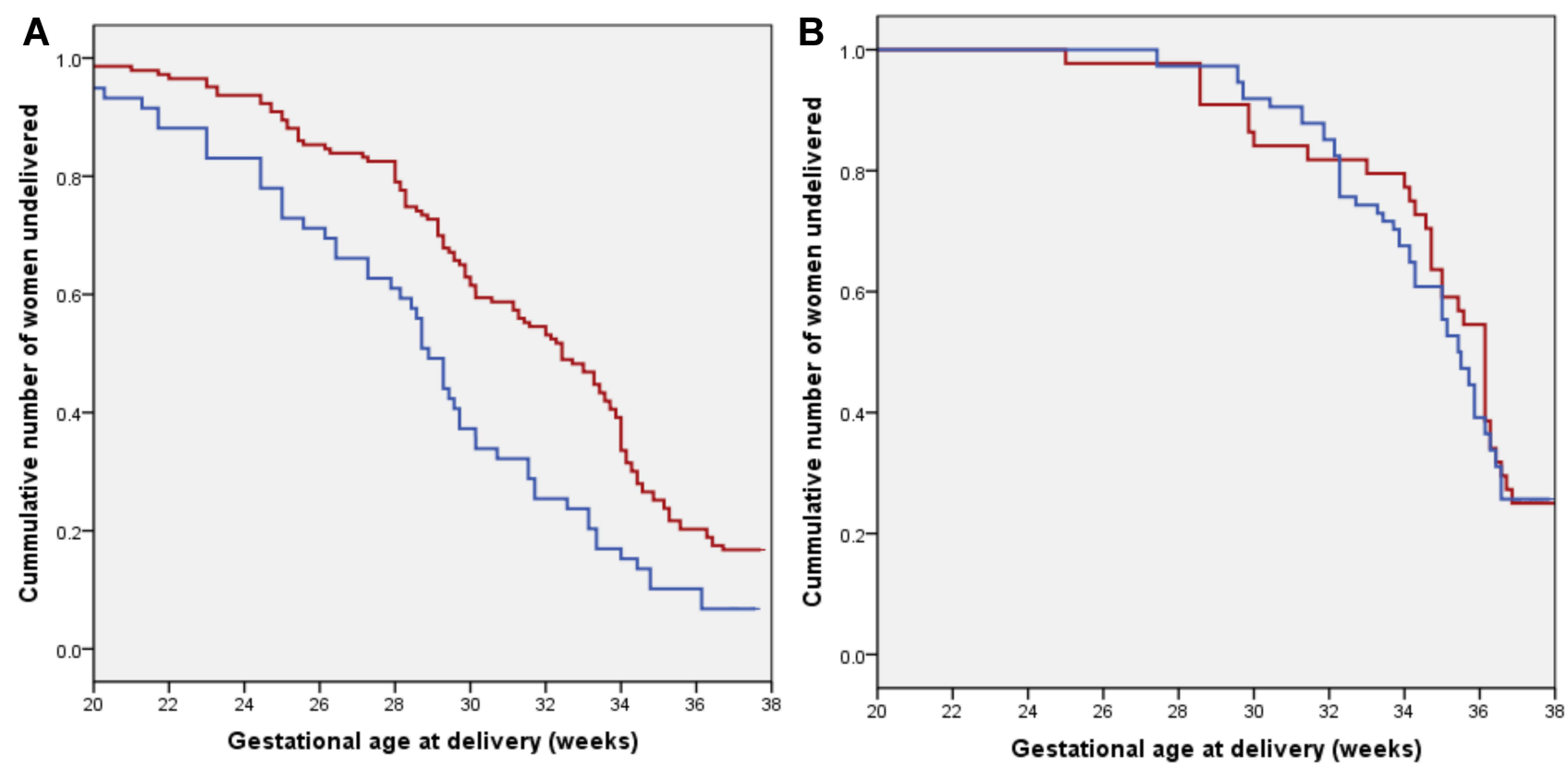

Figure $3 \mathrm{KM}$ curves generated from subgroup analysis of first short cervix diagnosis GA. Proportion KM curves in twin pregnancies in women with twin pregnancy and a short cervix with no delivery across gestation, treated with cervical cerclages (UIC group) compared with women with expectant management (control group). Subgroup analysis according to the first short cervix diagnosis GA; (A) Showed a GA of $\leqq 24$ weeks, and (B) showed a GA of $>24$ weeks. Group comparison using the Log rank test showed a significant difference $(\mathrm{HR}=2.29 ; \mathrm{Cl}=95 \%[\mathrm{I} .6 \mathrm{I}-3.26])$; and $\mathrm{p}=0.000)$ in $(\mathbf{A})$ and no difference between in $(\mathbf{B})$. Red curve cases with cerclage, blue curve cases with management treatment.

made on whether cerclage is effective in PTB prevention in twin pregnancy.

Certain studies on UIC in twin gestation ${ }^{10-14}$ show negative results in women with a $C L$ of $\leqq 25 \mathrm{~mm}$. Han et $\mathrm{al}^{11}$ compared 96 women in the cerclage group with 39 women in control group (GA of 14-26 weeks); no significant differences were detected in the overall PTB rates at $<32$ weeks $(15 \%$ vs $11.1 \%$; $=0.691)$ and $<34$ weeks $(30 \%$ vs $22.2 \% ; p=0.536)$. Saccone's study, ${ }^{12}$ which included three trials with 49 women who had twin gestations and a short CL, showed no statistically significant differences in the PTB rates at $<34$ weeks (adjusted OR $[\mathrm{aOR}]=1.17 ; \mathrm{CI}=95 \%$ [0.23-3.79]; $\mathrm{p}>0.05$ ) between the cerclage group and the no cerclage group. A metaanalysis ${ }^{13}$ including 23 trials and comprising 6626 women with twin pregnancies found that cerclage use could not significantly reduce neonatal death or the overall PTB risk at a GA of $<34$ weeks or $<37$ weeks. In Adams's research, ${ }^{14} 43$ patients received cerclage and 39 did not; patients with a $\mathrm{CL}$ of $\leqq 25 \mathrm{~mm}$ in the cerclage group showed no reduction in PTB rate at $<35$ weeks compared with the no cerclage group. A subsequent Cochrane review $^{15}$ published in 2014 examined five trials, two of which ( $\mathrm{n}=73$ women) assessed history-indicated cerclage and three of which $(\mathrm{n}=55$ women) assessed ultrasoundindicated cerclage. The review found no benefit of UIC in reducing preterm delivery in twin pregnancies at a GA of $<34$ weeks (Relative Risk [RR] $=1.16$; CI $=95 \%$ [0.443.36]; four trials, $n=98$ ). There was no reduction in the adverse neonatal outcome composite $(\mathrm{RR}=1.54 ; \mathrm{CI}=$ 95\% [0.58-4.11]). The authors concluded that there was no evidence regarding the usefulness of UIC in PTB risk reduction in twin gestation; however, further research was required due to the small trial number, each of which had a low number of patients. In the present study's overall sample comparison, UIC use in women with a CL of $<25 \mathrm{~mm}$ and twin gestation did not decrease the PTB rate at $<34$ weeks when compared with patients who were managed expectantly. Meanwhile, the subgroup analysis showed a significantly decreased PTB rate at $<34$ weeks and improved perinatal outcomes in the UIC group compared with the control group in women with a short cervix of $\leqq 15 \mathrm{~mm}$ or first short cervix diagnosis GA of $\leqq 24$ weeks. A CL of $<25 \mathrm{~mm}$ is considered the standard in singleton pregnancy cerclage placement indications; however, it is unclear whether $25 \mathrm{~mm}$ or $15 \mathrm{~mm}$ is the appropriate indication for twin gestation.

Certain studies supported our view that UIC is useful in women with twin pregnancy and a CL of $\leqq 15 \mathrm{~mm}$. Roman et $\mathrm{al}^{16}$ compared 32 cases who underwent UIC and 39 cases who did not undergo UIC; all cases had a CL of $\leqq 15 \mathrm{~mm}$ at a GA of $<24$ weeks. Here, the PTB rate at $<34$ weeks was 
significantly decreased $(50 \%$ vs $79.5 \%$, aOR $=0.51 ; \mathrm{CI}=$ $95 \%$ [0.31-0.83]) and pregnancy prolonged $(12.5 \pm 4.5$ weeks vs $8.8 \pm 4.6$ weeks; $p<0.001)$ in the UIC group when compared with the control group. ${ }^{16}$ In their research, ${ }^{14}$ Adams et al reported a significantly decreased PTB risk at $<35$ weeks ( $37 \%$ vs $71.4 \%$; adjusted $R R=0.49$ [0.26-0.93]) in patients with a CL of $<15 \mathrm{~mm}$. Furthermore, a recent meta-analysis conducted by Chunbo Li showed that cerclage placement in women with twin pregnancy and a CL of $<15 \mathrm{~mm}$ was associated with significant pregnancy prolongation by a mean difference of 3.89 weeks of gestation $\left(\mathrm{CI}=95 \%\right.$ [2.19-5.59]; $\mathrm{p}=0.000 ;$ and $\left.\mathrm{I}^{2}=0 \%\right)$ and $\mathrm{PTB}$ risk reduction at $<34$ weeks of gestation $(\mathrm{RR}=0.57$; $\mathrm{CI}=$ 95\% CI [0.43-0.75]; $\mathrm{p}=0.000$; and $\left.\mathrm{I}^{2}=0 \%\right) .{ }^{17}$ Houlihan's retrospective cohort study on consecutive diachronic diamniotic (DCDA) twin gestation in women with a short cervix at a GA of 16-24 weeks showed that the primary outcome PTB at $<32$ weeks was significantly lower in 40 cerclage cases than in 40 control cases ( $20 \%$ vs $50 \%$; RR $=0.40$; and $\mathrm{CI}=95 \%[0.20-0.80]) .{ }^{18} \mathrm{~A}$ retrospective cohort study on DCDA twin pregnancy in women with a short CL $(25 \mathrm{~mm})$ that included 33 cerclage cases and 13 non-cerclage cases found that the gestational age of delivery was significantly longer in the cerclage group than in the non-cerclage group $(86.09 \pm 41.32$ days vs $52.31 \pm 33.24$ days; $\mathrm{p}=0.014)$. Moreover, the PTB rate at $<34$ weeks in the cerclage group decreased significantly ( $19.0 \%$ vs $85.7 \%$; $p=0.003)$. UIC in DCDA twin pregnancy can decrease the PTB rate and prolong the gestational age of delivery. ${ }^{19}$

In a study on PTB risk factors in twins, an ultrasoundmeasured CL of $<25 \mathrm{~mm}$ at a GA of 24 weeks was noted as the strongest PTB predictor. ${ }^{19-23}$ In women with twin pregnancies, the risk of spontaneous PTB also increases with decreasing CL. ${ }^{6}$ Women with twin pregnancies and a short cervix are at extremely high risk for PTB. ${ }^{7}$ In the present research, the effect of cerclage placement on PTB rate reduction was significantly different at $\leqq 24$ weeks and at $>24$ weeks. It was found that, in women with twin gestation and a short cervix diagnosed at a GA of $\leqq 24$ weeks, cerclage placement had an overall beneficial effect on PTB rate reduction at $<34$ weeks as well as neonatal outcome improvement when compared with expectant management. However, in patients diagnosed at a GA of $>24$ weeks, the results in the two groups were comparable. Twins are the high-risk population for premature birth, and CL monitoring for this population should be strengthened. However, CL monitoring in twin pregnancy is not a routine practice in China. Based on the present data combined with the results of other studies, routine CL measurement during screening for Down's syndrome at a GA of 11-14 weeks as well as during screening for fetal macro malformations at a GA of 18-22 weeks (2024 weeks in China) is suggested.

The present study has several limitations. In present research neonatal outcome data were not all compiled, only birth weight and NICU admission rate were concluded, and other variables, such as intraventricular hemorrhage, necrotizing enterocolitis, neonatal sepsis, retinopathy of prematurity, bronchopulmonary dysplasia, periventricular leukomalacia, or use of mechanical ventilation were out of collection. Therefore, studies on the neonates in the UIC and control groups are not comprehensive. As a short TVU-detected CL has been shown as a good PTB predictor in twin pregnancy, the present study used the length as the only indicator. In addition to the $\mathrm{CL}$, the dilated diameter and elastic value of the cervix are also parameters reflecting cervix function. Several studies ${ }^{11,16}$ have confirmed that cervical dilation (especially $>1 \mathrm{~cm}$ ) and treatment with cervical cerclage may reduce the PTB rate in twin gestation. Several new parameters, such as elasticity and cervical dilation, will be applied in future studies on twin pregnancy.

In conclusion, the results of the present research demonstrated that UIC performance in women with twin pregnancy does not improve the maternal and neonatal outcomes. However, in women with a very short cervix ( $\leqq 15 \mathrm{~mm}$ ) or short cervix diagnosed at a GA of $\leqq 24$ weeks, UIC performance may significantly reduce the PTB rate at $<34$ weeks as well as perinatal morbidity and mortality.

\section{Funding}

This study was supported by Natural Science Foundation of Shanghai Municipal Health Commission (202040128) to Xiao-Lin Hua.

\section{Disclosure}

The authors report no conflicts of interest in this work.

\section{References}

1. McCurdy RJ, Baxter JK. Universal cervical length screening with a cervicometer to prevent preterm birth $<34$ weeks: a decision and economic analysis. $J$ Matern Fetal Neonatal Med. 2020;33:3670-3679. doi:10.1080/14767058.2019.1583202

2. Allotey J, Zamora J, Cheong-See F, et al. Cognitive, motor, behavioural and academic performances of children born preterm: a meta-analysis and systematic review involving 64061 children. BJOG. 2018;125:16-25. doi:10.1111/1471-0528.14832 
3. Martin JA, Osterman MJK. Describing the increase in preterm births in the United States, 2014-2016. NCHS Data Br. 2018;312:1-8.

4. Iams JD, Goldenberg RL, Meis PJ, et al. The length of the cervix and the risk of spontaneous premature delivery. National institute of child health and human development maternal fetal medicine unit network. $N$ Engl $J$ Med. 1996;334:567-572. doi:10.1056/NEJM1996022 93340904

5. Heath VC, Southall TR, Souka AP, Elisseou A, Nicolaides KH. Cervical length at 23 weeks of gestation: prediction of spontaneous preterm delivery. Ultrasound Obstet Gynecol. 1998;12:312-317. doi:10.1046/j.1469-0705.1998.12050312.x

6. To MS, Fonseca EB, Molina FS, Cacho AM, Nicolaides KH. Maternal characteristics and cervical length in the prediction of spontaneous early preterm delivery in twins. Am J Obstet Gynecol. 2006;194:1360-1365. doi:10.1016/j.ajog.2005.11.001

7. Kindinger LM, Poon LC, Cacciatore S, et al. The effect of gestational age and cervical length measurements in the prediction of spontaneous preterm birth in twin pregnancies: an individual patient level meta-analysis. BJOG. 2016;123:877-884. doi:10.1111/14710528.13575

8. Alfirevic Z, Stampalija T, Medley N. Cervical stitch (cerclage) for preventing preterm birth in singleton pregnancy. Cochrane Database Syst Rev. 2017;6:CD008991. doi:10.1002/14651858.CD008991.pub3

9. Suhag A, Berghella V. Cervical cerclage. Clin Obstet Gynecol. 2014;57(3):557-567. doi:10.1097/GRF.0000000000000044

10. Liu XR, Luo X, Xiao XQ, Qi HB. Cervical cerclage for preventing preterm birth in twin pregnancies. A systematic review and meta-analysis. Saudi Med J. 2013;34:632-638.

11. Han MN, O'Donnell BE, Maykin MM, Gonzalez JM, Tabsh K, Gaw SL. The impact of cerclage in twin pregnancies on preterm birth rate before 32 weeks. J Matern Fetal Neonatal Med. 2019;32:2143-2151. doi:10.1080/14767058.2018.1427719

12. Saccone G, Rust O, Althuisius S, Roman A, Berghella V. Cerclage for short cervix in twin pregnancies: systematic review and meta-analysis of randomized trials using individual patient-level data. Acta Obstet Gynecol Scand. 2015;94:352-358. doi:10.1111/ aogs. 12600

13. Jarde A, Lutsiv O, Park CK, et al. Preterm birth prevention in twin pregnancies with progesterone, pessary, or cerclage: a systematic review and meta-analysis. BJOG. 2017;124:1163-1173. doi:10.1111/1471-0528.14513
14. Adams TM, Rafael TJ, Kunzier NB, Mishra S, Calixte R, Vintzileos AM. Does cervical cerclage decrease preterm birth in twin pregnancies with a short cervix? J Matern Fetal Neonatal Med. 2018;31:1092-1098. doi:10.1080/14767058.2017.1309021

15. Rafael TJ, Berghella V, Alfirevic Z. Cervical stitch (cerclage) for preventing preterm birth in multiple pregnancy. Cochrane Database Syst Rev. 2014;9:CD009166.

16. Roman A, Rochelson B, Martinelli P, et al. Cerclage in twin pregnancy with dilated cervix between 16 to 24 weeks of gestation: retrospective cohort study. Am J Obstet Gynecol. 2016;215:98.e198.e11. doi:10.1016/j.ajog.2016.01.172

17. Li C, Shen J, Hua K. Cerclage for women with twin pregnancies: a systematic review and metaanalysis. Am J Obstet Gynecol. 2019;220:543-557.e1. doi:10.1016/j.ajog.2018.11.1105

18. Houlihan C, Poon LC, Ciarlo M, Kim E, Guzman ER, Nicolaides KH. Cervical cerclage for preterm birth prevention in twin gestation with short cervix: a retrospective cohort study. Ultrasound Obstet Gynecol. 2016;48:752-756. doi:10.1002/ uog. 15918

19. Wu FT, Chen YY, Chen CP, Sun FJ, Chen CY. Outcomes of ultrasound-indicated cerclage in twin pregnancies with a short cervical length. Taiwan J Obstet Gynecol. 2020;59:508-513. doi:10.1016/ j.tjog.2020.05.007

20. Goldenberg RL, Iams JD, Miodovnik M, et al. The preterm prediction study: risk factors in twin gestations. National institute of child health and human development maternal-fetal medicine units network. Am J Obstet Gynecol. 1996;175:1047-1053. doi:10.1016/ S0002-9378(96)80051-2

21. Souka AP, Heath V, Flint S, Sevastopoulou I, Nicolaides KH. Cervical length at 23 weeks in twins in predicting spontaneous preterm delivery. Obstet Gynecol. 1999;94:450-454. doi:10.1016/ s0029-7844(99)00277-x

22. Imseis HM, Albert TA, Iams JD. Identifying twin gestations at low risk for preterm birth with a transvaginal ultrasonographic cervical measurement at 24 to 26 weeks' gestation. Am J Obstet Gynecol. 1997;177:1149-1155. doi:10.1016/S0002-9378(97)70032-2

23. Guzman ER, Walters C, O'reilly-Green C, et al. Use of cervical ultrasonography in prediction of spontaneous preterm birth in twin gestations. Am J Obstet Gynecol. 2000;183:1103-1107. doi:10.1067/ mob.2000.108896
International Journal of General Medicine

\section{Publish your work in this journal}

The International Journal of General Medicine is an international, peer-reviewed open-access journal that focuses on general and internal medicine, pathogenesis, epidemiology, diagnosis, monitoring and treatment protocols. The journal is characterized by the rapid reporting of reviews, original research and clinical studies across all disease areas. The manuscript management system is completely online and includes a very quick and fair peer-review system, which is all easy to use. Visit http://www.dovepress.com/ testimonials.php to read real quotes from published authors. 